\title{
Why are there not more women consultants?
}

\author{
There could be -if all regions did as well as the best
}

Women prefer to see women doctors and the patient's charter gives them the right to do so. ${ }^{1}$ But women make up only $15.5 \%$ of the consultants in the United Kingdom, and the NHS Management Executive is finding that percentage stubbornly resistant to change. ${ }^{2}$

In 1991 the Department of Health became the first government department to sign up to Opportunity 2000, a central initiative to increase "the quality and quantity of women's participation in the workforce." The NHS, an employer of 750000 women, set itself the goal of increasing the percentage of women consultants to $20 \%$ by the end of 1994, necessitating an annual increase of $10 \%$. It also committed itself to accelerating the rate of increase in the number of women consultants in surgical specialties (where women hold $3 \cdot 7 \%$ of posts) from the current $9 \cdot 7 \%$ per year to $15 \%$ per year. These goals, said the management executive, were "challenging, demanding and measurable, but most importantly achievable."

It was, therefore, demoralising for women doctors to be told last week at the management executive's first conference for women in medicine that the overall goal will be impossible to achieve. One is that women are still not trying to become consultants. The culture of hospitals appears male, competitive, and hostile to them. Women at the conference spoke of having wanted to specialise in hand surgery and in obstetrics and gynaecology but instead opting for careers that let them have a family and social life. There are still not enough ordinary women at the top of many specialties to act as role models and pull women up after them.

Some women at the conference thought that it was unhelpful to say that women needed a different deal from men; they wanted careers in hospital medicine to be made easier for both sexes. In particular, they felt that improving the status of part time training would make it more acceptable to men.

The Department of Health is committed to quadrupling the number of part time posts for career registrars by 1995 . But, although it has tried to simplify application procedures, the process is still bureaucratic and protracted. As it is available only for "well founded individual reasons, such as domestic commitments, disability or ill health," it is automatically seen as an option for unambitious women. ${ }^{3}$ One speaker recounted anecdotal evidence that male doctors who wanted to look after their children were more likely than women to be refused part time training.

But if it is so difficult for women to get to the top why have some regions been so much more successful in encouraging them than others? North West Thames, South West Thames, and Oxford regions already have women in over $20 \%$ of consultant posts (NHS Women's Unit, personal communication). The conference heard that between January and September this year Oxford gave $54 \%$ of its advertised consultant posts to women. ${ }^{4}$ The region now has three women consultants in general surgery. Its well publicised part time training programme has been going since 1966, and both doctors and managers in the region are rightly proud of it. There are other pockets of progress. The Northern region now employs nearly half of England's 13 female orthopaedic surgeons. But the conference heard that while some regions positively encourage women-in Wessex, for example, women senior registrars are given help with their interview technique before they apply for consultant posts-others simply ignore Opportunity 2000's goals. In East Anglia and Yorkshire regions, for example, only $12 \%$ of consultants are women. Such poor records must indicate prejudice and discrimination against women, and these regions should feel ashamed.

Outside medicine, too, progress is still slow. The Labour party - faced with a paucity of women members of parliament -agreed recently to double the number of its women members of parliament by the next election. Half of all Labour seats that become vacant must now be filled from a shortlist of women. The Equal Opportunities Commission is still discussing the legality of this scheme to discriminate in favour of women. But political parties are generally exempt from the 1975 Sex Discrimination Act. The NHS is not and so can offer only encouragement and training for women.

One of the most useful things that it could do, along with the royal colleges and postgraduate deans, is to be more imaginative over flexible training. Why does part time training have to take twice as long? Women at the conference said that once they had had children they would like to vary the number of hours they worked: this could mean they might want to work two days a week for one year but perhaps four days a week the next year. They wanted accreditation to be awarded on the basis of experience and not years. Royal colleges need to follow the example of the Royal College of Obstetricians and Gynaecologists in appointing a national adviser on flexible training. Only the Royal College of Psychiatrists has a trainee committee that has representation on the college's other committees. The colleges need to hear the concerns of both men and women junior doctors. It may 
be symptomatic of their unwillingness to listen that while the presidents of all the medical royal colleges were invited to the conference, only Dr Fiona Caldicott, president of the Royal College of Psychiatrists, was present.

Nevertheless, some of the changes scheduled to happen in the NHS are likely to make it easier for women to become consultants. The Calman report, with its promise of structured and geographically stable training and the achievement of specialist status after seven years of postgraduate training, may encourage women to defer having children until they are consultants. The new deal on junior doctors' hours, even if its impact is limited, could at least encourage shift work and other more flexible working patterns.

The increasing power of purchasers may also benefit women. Purchasers are right to insist that hospitals provide women consultants for their patients and if necessary they can refer a patient elsewhere to find an appropriate doctor. Purchasers should sit on the committees for consultant appointments and ensure that appointments procedures are fair to women.

Women themselves have always emphasised the importance of mentors. They need ordinary women as role models and they need to be exposed to them at medical school. They need the informal support that nudges men up their career ladders. Too often they are excluded from the dining and travel clubs that male doctors belong to and denied inside information about what career moves they should be making.

The NHS has another Opportunity 2000 goal which it is more likely to reach. By the end of 1994 the number of women in general management posts should have increased from $18 \%$ in 1991 to $30 \%$. There are no national figures available, but the NHS Women's Unit has monitored appointments to top managers' jobs between March 1992 and June 1993. Women filled 34 out of 77 posts. The conference heard that managers appreciate that women have valuable management skills such as the ability to collaborate and adapt to flexible working patterns.

In contrast, the medical profession still seems content to wait for the few exceptional women to follow the men's path to the top. Women at the conference said that there was no point trying to increase their numbers if the path wasn't made easier. As one woman manager said, only when there are as many mediocre women at consultant level as there are mediocre men will Opportunity 2000 come of age.

Asssitant editor, $B M F$

LUISA DILLNER

1 Lurie N, Slater J, McGovern P, Ekstrum J, Quam L, Margolis K. Preventative care for women $N$ Engl f Med 1993;329:478-82.

2 NHS Management Executive. Women in the NHS. London: Department of Health, 1992.

3 NHS Management Executive. Flexible training. Report of the joint working party. London Department of Health, 1993.

4 Oxford Regional Health Authority. Opportunity 2000: Goal 3. Oxford: Oxford RHA, 1993.

\section{Reye's syndrome 30 years on}

\section{Possible marker of inherited metabolic disorders}

In the 30 years since R D K Reye and colleagues reported children with acute encephalopathy and visceral fatty infiltration ${ }^{1}$ intensive investigation of this curious biphasic illness has left many unanswered questions. Only small numbers of children (1-6 cases/million children $<16$ years of age) develop Reye's syndrome after an apparently innocuous, viral prodrome. ${ }^{2}$ Profuse vomiting marks the onset of an encephalopathy, which may progress through extreme lethargy and combative behaviour to coma. Hepatic function is disturbed with increased concentrations of serum transaminases and blood ammonia; while coagulopathy is virtually universal and hypoglycaemia common, jaundice is rare. ${ }^{3}$ At necropsy the brain is swollen and the liver appears pale because of intense microvesicular, panlobular fatty change. ${ }^{1}$

Liver biopsy in the acute phase shows swollen and pleomorphic mitochondria, which distinguishes Reye's syndrome from other acute metabolic encephalopathies. ${ }^{4}$ Although the insult that initiates mitochondrial dysfunction is unknown, $\beta$ oxidation is apparently blocked at multiple sites. Short and medium chain acyl CoA esters, which sequester free coenzyme $\mathrm{A}$, accumulate within mitochondria. ${ }^{5}$ This reduces energy production and ATP within the mitochondria, which may prevent proper processing of imported protoenzymes and assembly of holoenzyme complexes on the inner membrane. ${ }^{6}$ Consequently, catalytic activities fall and many intermediary pathways-including ureagenesis and gluconeogenesis-are disrupted.

Diagnostic criteria on both sides of the Atlantic are unexplained, non-inflammatory encephalopathy in a child under 16 with serum hepatic transaminases or blood ammonia concentrations greater than three times the upper normal limit, or typical histopathology. In the British Isles, case reporting to the British Paediatric Surveillance Unit ${ }^{2}$ has had four important benefits. Firstly, striking epidemiological differences from United States data have been recorded-in the United Kingdom and the Republic of Ireland babies and preschool children have tended to be affected whereas in the United States cases in school aged children with influenza prodromes have been more common. ${ }^{7}$ Secondly, reported cases formed the basis for a risk factor study, which, despite scientific scepticism, confirmed a significant association between Reye's syndrome and aspirin use during the prodrome. ${ }^{8}$ Thirdly, since 1985, diagnosis of Reye's syndrome has been revised in favour of an inherited metabolic disorder in one quarter of cases satisfying the case definition. Finally, as an investigative tool case reporting to the surveillance unit has been an outstanding success. Since 1986 its portfolio has been enlarged to research many other rare disorders. Similar schemes have been established in Australia, Germany, and the Netherlands (personal communication Susan Hall).

Recently, the number of reported cases on each side of the Atlantic has fallen. In the United Kingdom this seemed to follow warnings to health professionals and the public against giving aspirin to children under $12 .{ }^{9}$ This fall has been striking in Northern Ireland, which contributed $20 \%$ of cases in 1984-6 but only $1 \%$ in $1990-1 .^{2}$ Heightened awareness of inherited metabolic disorders by paediatricians and the ability of more centres to perform diagnostic tests may have encouraged this trend. ${ }^{10}$

Today the investigation of patients presenting with Reye's syndrome should be informed by the fact that specific enzyme 